\title{
Lagged and Contemporaneous Reserve Accounting: An Alternative View
}

\section{DANIEL L. THORNTON}

$\mathbf{R}$

ECENT volatility in both money and interest rates has prompted the Federal Reserve Board to adopt a plan for contemporaneous reserve accounting (CRA). "This move follows a number of requests from both inside and outside the Federal Reserve System to return to CRA. These requests stem from empirical investigations that show that both money and interest rates became more volatile after the adoption of lagged reserve accounting (LRA) in September 1968, and from theoretical work that shows an increase in volatility of money and possibly interest rates when the System moves from CRA to LRA. ${ }^{2}$

Daniel L. Thornton is a senior economist at the Federal Reserve Bank of St. Louis. John G. Schulte provided research assistance.

'In the Board's plan, CRA applies only to transactions accounts. Reserve requirements on time and savings accounts will continue to be set on a lagged basis. For a concise summary of the Board's plan for CRA, see Michaet R. Pakko, "Lagged and Contemporaneous Reserve Accounting. Money Market Stability and Monetary Control: A Topical History of Recent U.S. Monetary Policy, Federal Reserve Bank of Richmond (1983).

The empirical work includes Albert E. Burger, "Lagged Reserve Requirements: Their Effects on Federal Reserve Operations, Money Market Stability, Member Banks and the Money Supply Process," unpublished paper for the Federal Reserve Bank of St. Louis (1971); Warren L. Coats, "Lagged Reserve Accounting and the Money Supply Mechanism," Journal of Money, Credit and Banking (May 1976), pp. 167-180; Edgar L. Feige and Robert McGee, "Money Supply Control and Lagged Reserve Account. ing." Journal of Monety, Credit and Banking (November 1977), pp. 536-5l; and William Poole and Charles Lieberman, "Improving Monetary Control," Brookings Papers on Economic Activity (2:1972), pp. 293-335.

The theoretical work includes Daniel E. Laufenberg, "Contemporary Versus Lagged Reserve Accounting," Journal of Money, Credit and Banking (May 1976), pp. 239-45; Stephen F. LeRoy, "Monetary Control Under Lagged Reserve Accounting," Southern Economic Journal (October 1979), pp. 460-70; Willian Poole. "Federal Reserve Operating Procedures: A Survey and Evaluation of the Historical Record Since October 1979, "Journal of Money, Credit and Banking (November 1982, part 2), pp. 575-96; and Bernett T. McCallum and James $G$. Hoehn, "Instrument Choico for Money Stock Control With Contemporaneous and Lagged
Recently, Feige and McGee presented evidence that the effect of LRA on federal funds rate volatility has not been substantial when week-to-week relative changes are considered. ${ }^{3}$ Thus, previous empirical work on the volatility of short-term interest rates under LRA, which considered longer time periods of absolute measures of variability, may be misleading. This article presents a theoretical argument to further support this conclusion. It should be emphasized that only the case of a move from CRA to LRA is considered, but the premise applies equally well to the return to CRA.

The outline of the article is as follows: First, the rationale for claiming that the case against LRA is overstated is presented. This idea is then formalized in the context of a simple linear stochastic model of the money supply process. Finally, the variability of various interest rates and money is examined and some concluding comments are made.

\section{THE WATONA}

The concern that the theoretical case against LRA is overstated is based on the application of a simple principle: additional constraints are binding only if indi-

Reserve Requirements," Joumal of Money, Credit and Banking (February 1983), pp. 96-101.

Three recent empirical studies that employ stochastic model simulations suggest that the gain to monetary control from the retum to CRA will be modest under a nonborrowed reserve operating target. See David Lindsey and others, "Monetary Control Experience Under the New Operating Procedures," Federal Reserve Staff Study, New Monetary Control Procedures, February 1981. pp. 53-56; David S. Jones, "Contemporaneous vs. Lagged Reserve Accounting: Implications for Monetary Control," Economic Review, Federal Reserve Bank of Kansas City, November 1981, pp. 3-. 19; and Peter Tinsley and others, "Policy Robustness: Specification and Simulation of a Monthly Money Market Model," Journal of Money, Credit and Banking (November 1982, part 2), pp. 82956 .

${ }^{3}$ See Edgar L. Feige and Robert McGee, "Federal Reserve Policy and Interest Rate Instability," The Financial Review (May 1982), pp. $50-62$ 
viduals behave differently than they would in the absence of these constraints. ${ }^{4}$ That is, if banks already were behaving in much the same way that LRA permitted them to, then the effect of its introduction on individual and aggregate behavior would be small.

In order to see why this is the case, consider how a depository institution might manage its reserve position under CRA. Such an institution would be required to keep a fraction of its current checkable and time and savings deposit liabilities in the form of reserves (vault cash and deposits with the Federal Reserve) ${ }^{5}$ When the institution makes loans and investments, it creates deposits. Thus, it is usually presumed that there is a direct link between the institution's current lending and investment activities and its current holdings of reserves. In a simplified and, perhaps, naive form, institutions lend only the amount of their excess reserves. ${ }^{6}$ Some argue that LRA severs this link. Under LRA, depository institutions' reserve requirements are based on deposit liabilities from a preceding period. Depository institutions are free to make all the loans and investments they desire in the current period without affecting their current reserve requirements. ${ }^{7}$

A depository institution's decision to make additional loans and investments need not be closely related to its current holdings of reserves. In the short run it can obtain additional reserves by purchasing federal funds, borrowing from the Federal Reserve, selling Treasury securities, managing its liabilities - such as marketing certificates of deposits (CDs) more aggressively - or by temporarily holding fewer excess reserves than it

\footnotetext{
${ }^{4}$ Nearly all of the theoretical work on this subject starts with a model that is completely static. LRA is introduced, transforming the static model to a dynamic one. It is clear that the conclusions of these models are based, in part, on the fact that they introduce a dynamic structure to an otherwise static model; hence, these models preclude the possibility that LRA introduces a dynamic structure that is, at least in part, redundant. This paper considers this possibility.

${ }^{5}$ Because of the Monetary Control Act of 1980, depository institutions need not hold reserves directly on deposit with the Federal Reserve. Instead, they may hold them with another depository institution on a pass-through basis.

${ }^{6}$ Actually, each individual bank has its own short-run deposit multiplier, which enables it to lend more or less than its excess reserves in the short run. See Boris P. Pesek and Thomas $\mathrm{R}$. Saving, The Foundations of Money and Banking (Mac Millan 1968), chapters 12 and 13.

${ }^{7}$ For a discussion of this possibility, see R. Alton Gilbert, "Lagged Reserve Requirements: Implications for Monetary Control and Bank Reserve Management," this Review (May 1980), pp. 7-20. Furthermore, some argue that, because of this, the Federal Reserve can only accommodate deposit expansion or contraction under LRA. For an alternative view, see Daniel L. Thornton, "Simple Analytics of the Money Supply Process and Monetary Control," this Review (October 1982), pp. 22-39.
}

would otherwise like to hold. Thus, even under CRA, a depository institution's decision to make current loans and investments is not constrained by its current holdings of reserves. ${ }^{8}$

Of course, if there was a reserve deficiency and if it were to run for an extended period of time, the institu tion would have to adjust its lending and investment activities to bring deposits into line with its reserves. Furthermore, since only three of the above techniques of reserve adjustment relieve reserve pressure on the system as a whole, depository institutions eventually may find it necessary to adjust their lending and investment activities if rates on short-term reserve adjustment assets rise relative to the institutions ' lending rates. $^{9}$

Thus, depository institutions must eventually adjust their reserve positions by adjusting their loan and investment portfolios. For short-run (week-toweek) changes, however, they can rely on either the money market, changes in their holdings of excess reserves or the discount window. The link between current lending and investment activities and current reserves need not be strong.

\section{A SIMPLE STOCHASTIC MODEL}

In this section, the conjecture of the previous section is formalized with a simple linear stochastic model of the money stock. The model is intended only to capture the essential features of money stock determination under CRA and LRA and to illustrate the basic restriction associated with moving from CRA to LRA. ${ }^{10}$ In this sense, the model is illustrative and is not

\footnotetext{
${ }^{8}$ Spind and Tarhan also argue, along similar lines, that the case against LRA may be overstated. Furthermore, they provide some empirical evidence of the extent to which banks rely on each of the reserve adjustment mechanisms listed above. See Paul $A$. Spindt and Vefa Tarhan, "Bank Earning Asset Behavior and Causitity Between Reserves and Money: Lagged Versus Contemporaneous Reserve Accounting," Journal of Monetary Economics, forthcoming.

${ }^{9}$ Both federal funds trading and reducing the level of excess reserves tend to reduce the average level of excess reserves for the system as a whole. This allows a given reserve base to support a larger money stock. Discount window borrowing increases the total reserve base of the system.

107he essential features are: (1) a contemporaneous link between the reserve aggregate and the money stock, even under LRA, (2) an explicit dynamic structure unter both CRA and LRA, and (3) random disturbances on both the supply and demand side. In this model, the contemporaneous link between the reserve aggregate and the money stock is established only through the excess reserve equation. This is done as a matter of convenience. The link could be established through the currency equation. See Thomton, "Simple Analytics of the Money Supply Process."
} 
presumed to be a complete description of money stock determination.

The model consists of the following four equations:

(1) $\mathbf{R}_{\mathrm{t}}=\mathbf{R R}_{\mathrm{t}}+\mathbf{E R}_{\mathrm{t}}$

(2) $\mathrm{RR}_{\mathrm{t}}=\theta \mathrm{r} \mathrm{M}_{\mathrm{t}}+(1-\theta)+\mathrm{M}_{\mathrm{t}-1}$

$$
\theta=0,1
$$

(3) $\mathrm{ER}_{\mathrm{t}}=\delta \mathrm{M}_{\mathrm{t}}+\rho \mathrm{i}_{\mathrm{t}}-\lambda\left(\mathrm{RR}_{\mathrm{t}}-\mathrm{FM}_{\mathrm{t}-1}\right)+u_{\mathrm{t} t}$

$$
\delta>0, \rho \leq 0,0 \leq \lambda \leq 1
$$

(4) $\mathrm{M}_{\mathrm{t}}=\beta \mathrm{Y}_{\mathrm{t}}+\alpha \mathrm{i}_{\mathrm{t}}+\mu \mathrm{M}_{\mathrm{t}-\mathrm{l}}+\mathrm{u}_{\mathrm{z}, \mathrm{t}}$

$$
\beta>0, \alpha \leq 0, \mu>0 \text {. }
$$

The random errors, $\mathrm{u}_{\mathrm{e} t \mathrm{t}}$ and $\mathrm{u}_{\mathrm{m} t}$ are assumed to have zero expected values and finite variances, $\sigma_{\mathrm{e}}^{2}$ and $\sigma_{\mathrm{m}}^{2}$, respectively. Equations 1 through 3 represent the money supply process. ${ }^{11}$ The first defines total reserves as required plus excess reserves. The second defines required reserves as some required reserve ratio, $r$, times the money stock; the parameter $\theta$ allows for either CRA $(\theta=1)$ or LRA $(\theta=0)$. In the third equation, excess reserves are proportionally related to the current money stock and inversely related to the market interest rate, $i_{\mathbf{t}}$. The excess reserve equation differs from most in that depository institutions make some proportional adjustment, $\lambda$, to changes in required reserves. If $\lambda=1$, depository institutions do not adjust their current deposits to changes in required reserves. Instead, they absorb such changes by altering their holdings of excess reserves. ${ }^{12}$ Equation 4 is the standard short-run money demand specification, where the market equilibrium condition has been imposed.

Equation 3 is important because it allows the LRA model to be given as a special case of the CRA model $(\theta=1)$. This can be seen by solving for the equilibrium money stock and interest rate. The reduced forms for the equilibrium money stock and interest rate are given by equations 5 and 6 :

$$
\begin{aligned}
\mathrm{M}_{\mathrm{t}} & =\frac{\alpha}{\Delta_{0}} \mathrm{R}_{\mathrm{t}}+\frac{\beta \rho}{\Delta_{0}} \mathrm{Y}_{\mathrm{t}}+\frac{\beta \mu-\alpha(\mathrm{r}(1-\lambda)(1-\theta)+\lambda \mathrm{r})}{\Delta_{0}} \mathrm{M}_{\mathrm{t}-1} \\
& -\frac{\alpha}{\Delta_{0}} \mathrm{u}_{\mathrm{z} t}+\frac{\rho}{\Delta_{0}} \mathrm{u}_{\mathrm{iz1}}
\end{aligned}
$$

\footnotetext{
"It should be noted that this molel contains only a one-period lag, whereas, as implemented. LRA has a two-period lag. The oneperiod lag was adopted for computational convenience.

${ }^{12}$ Excess reserves are treated as a buffer-stock asset. Furthermore, they are assured to be strictly positive and sufficient to deal with any recuired reserve surprises due to random fuctuations in $u_{e t}$ or $\mathrm{u}_{\mathrm{m}}$. This model is kept simple by considering explicitly only reserve adjustment through excess reserve holdings. It should be clear, however, that the other adjustment mechamins could be modeled.
}

$$
\text { (6) } \begin{aligned}
\mathrm{i}_{\mathrm{t}} & =\frac{1}{\Delta_{0}} \mathrm{R}_{\mathrm{t}}-\frac{\beta(\theta \mathrm{r}(1-\lambda)+\delta)}{\Delta_{0}} \mathrm{Y}_{\mathrm{t}} \\
& =\frac{(\mu-1) \theta(1-\lambda) \mathrm{r}+\delta \mu+\mathrm{r}}{\Delta_{0}} \mathrm{M}_{\mathrm{t}-1}-\frac{1}{\Delta_{0}} \mathrm{u}_{\mathrm{t}} \\
& -\frac{\theta \mathrm{r}(\mathbf{l}-\lambda)+\delta}{\Delta_{0}} \mathrm{u}_{\mathrm{mt}}, \text { where } \Delta_{0}=\alpha(\mathrm{r} \theta(1-\lambda)+\delta)+\rho<0 .
\end{aligned}
$$

Note that equation 5 is the same if $\theta=0$ or if $\lambda=1$; the same is true of equation 6 . That is, the equilibrium money stock and interest rate are the same in a model with CRA, where depository institutions do not initially alter their current lending and investment activities to adjust their reserve positions $(\lambda=1)$ as in a model with LRA. Thus, imposing lagged reserve accounting on the above model by letting $\theta=0$ when $\lambda=1$ has no effect on the money supply; depository institutions would not have altered their lending and investment activities immediately in response to changes in total reserves anyway. The imposition of LRA is redundant if $\lambda=1 .{ }^{13}$

\section{Effects of LRA on the Money Supply}

Solving the first three equations, the money supply, $\mathbf{M}^{s}$, is given by

(7) $M_{\mathrm{t}}^{\mathrm{s}}=\frac{1}{\Delta_{1}} \mathrm{R}_{\mathrm{t}}-\frac{(\mathrm{r}-(1-\lambda) \theta \mathrm{r})}{\Delta_{\mathrm{l}}} \mathrm{M}_{\mathrm{t}-1}-\frac{\mathrm{p}}{\Delta_{1}} \mathrm{i}_{\mathrm{q}}-\frac{1}{\Delta_{\mathrm{l}}} \mathrm{E}_{\mathrm{et}}$,

where $\Delta_{1}=\theta \mathrm{r}(1-\lambda)+\delta$. A comparison of the money supply when $\theta=1$ and when $\theta=0$ reveals basic differences between LRA and CRA that should be noted. First, the money supply schedule is more interestsensitive under LRA, as figure 1 illustrates.

Second, the multiplier on the reserve aggregate is smaller for CRA than for LRA. ${ }^{14}$ Thus, a given change in the reserve aggregate shifts the money supply schedule further under LRA. The shift is significantly further so that the initial change in the equilibrium money stock is greater under LRA (figure 1). Thus, a given change in the policy variable (or any exogenous shock on the supply side) produces a larger initial

\footnotetext{
${ }^{13}$ There is an implicit assumption that bank reserve adjustment behavior is invariant to the reserve accounting system. Recently, Spindt and Tarhan have provided empirical evidence that this was the case after LRA was introduced in 1968. It is interesting to note, however, that their evidence indicates that banks relied less on adjusting current loans and investments and more on changes in excess reserves, federal funds, discount window borrowings and CDs after LRA was introduced. The differences, however, were not statistically significant. See Spindt and Tarhan, "Bank Earning Asset Behavior and Causality Between Reserves and Money."

1.whe mutipliers are $1 / \delta$ and $1 /(\mathrm{r}(1-\lambda)+\delta)$ for LRA and CRA, respectively.
} 


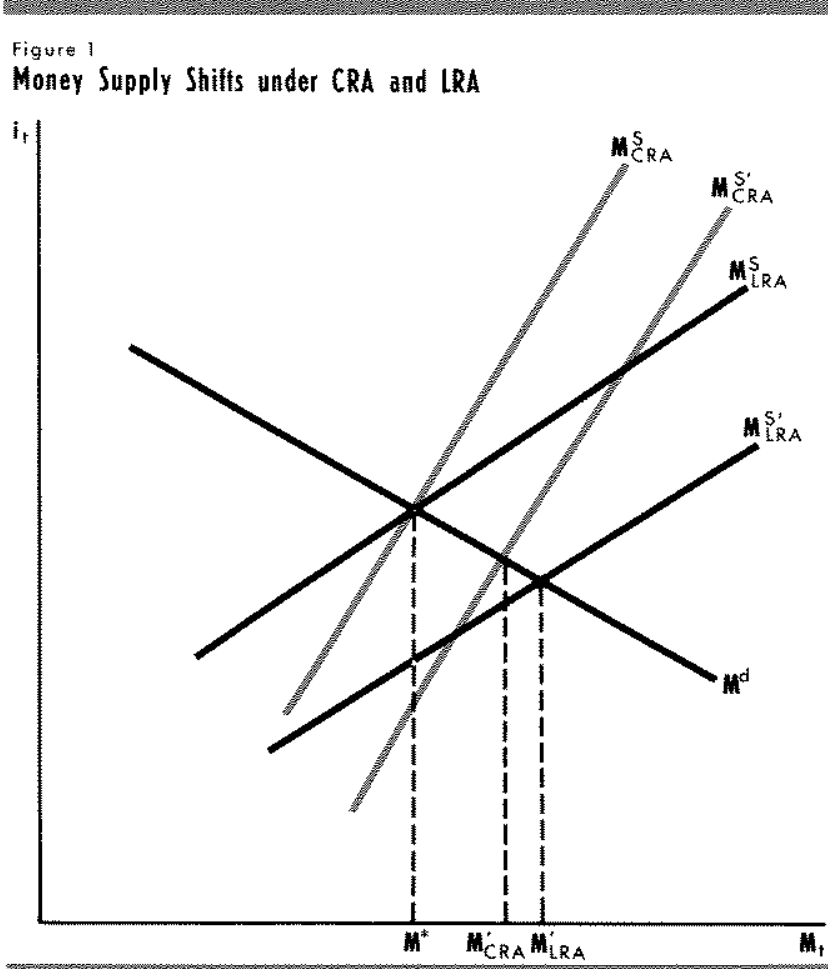

change in the money stock and the interest rate under LRA.

Finally, the money supply equation is dynamic under LRA but not under CRA unless $\lambda>0$. This is an important difference. If the money supply schedule is assumed to be static, as is common for CRA specifications, then the adjustment from initial to long-run equilibrium is determined solely by the dynamic structure of the demand for money. If $\mu$, the money demand coefficient on lagged money, is positive (as nearly all the empirical work on the money demand equation suggests), then the initial equilibrium under CRA will be below the long-run equilibrium. ${ }^{15}$ If only a static model is considered (CRA with $\lambda=\mu=0$ ) then the imposition of LRA introduces a dynamic structure to the model. ${ }^{16}$ In this case, the initial equilibrium money

${ }^{15}$ This would not be the case if there were strong distributed lag effects on inkerest rates in the money demand equation dominating the distributed lag effects on the money supply. However, sich effects seem absent from most empirical estimates of money demand. For an exception, see Daniel L. Thornton, "Maximum Likelihood Estimates of a Partial Adjustment-Adaptive Expectations Model of the Demand for Money, "Review of Economics and Statistics (May 1982), pp. 325-29.

16It should be noted that neither LRA nor an excess reserve equation like equation 3 is necessary to get a lagged effect on the money supply. All that is required is that there be a lagged effect in the public's demand for a component of a particular monetary aggregate or reservable asset. For example, a positive coefficient on either lagged currency or the time deposits in a standard money stock model will be sufficient to cause an initial overshooting of the stock would be above its long-run equilibrium: depository institutions initially would overexpand the money stock and oscillate toward long-run equilibrium. ${ }^{17}$

LRA allows the current money stock to affect the future money supply. In the complete model, with lagged money in the money demand function, the long-run equilibrium can be above or below the initial equilibrium. The particular outcome depends on the relative strength of the supply-side and demand-side effects.

These results can be illustrated by noting that equation 5 can be lagged and substituted into equations 5 and 6 to obtain the dynamic equations for the equilibrium money stock and interest rate:

$$
\begin{aligned}
& M_{t}=\frac{\alpha}{\Delta_{0}} \sum_{j=0}^{\infty} \xi^{j} R_{t-j}+\frac{\beta \rho}{\Delta_{0}} \sum_{j=0}^{\infty} \xi^{j} X_{i-j} \\
& -\frac{\alpha}{\Delta_{0}} \sum_{j=0}^{\infty} \xi^{j} u_{e t-j}+\frac{\rho}{\Delta_{0}} \sum_{j=0}^{\infty} \xi^{j} k_{m t-j} \\
& \text { (9) } \mathrm{i}_{\mathrm{t}}=\frac{1}{\Delta_{0}} \mathrm{R}_{\mathrm{t}}-\frac{\alpha \eta}{\left(\Delta_{0}\right)^{2}} \sum_{j=0}^{\infty} \xi^{j} \mathrm{R}_{\mathrm{i}-\mathrm{j}-\mathrm{t}} \\
& -\frac{\beta(\theta \mathrm{r}(1-\lambda)+\delta)}{\Delta_{0}} \mathrm{Y}_{1}-\frac{\eta \beta \rho}{\left(\Delta_{0}\right)^{2}} \sum_{j=0}^{\infty} \xi^{j} \mathrm{Y}_{\mathrm{t}-\mathrm{j}-1} \\
& -\frac{1}{\Delta_{0}} u_{c t}+\frac{\alpha \eta_{i}}{\left(\Delta_{0}\right)^{2}} \underset{j=0}{\infty} \xi^{j} u_{e t-j-1} \\
& -\frac{\mathrm{r} \theta(\mathrm{I}-\lambda)+\delta}{\Delta_{0}}-\mathrm{u}_{\mathrm{m} t}-\frac{\eta \rho}{\left(\Delta_{0}\right)^{2}} \sum_{j=0}^{\infty} \xi^{j} \mathrm{u}_{\mathrm{m} m-j-1},
\end{aligned}
$$

where $\xi=\frac{\rho \mu-\alpha(r(1-\lambda)(1-\theta)+\lambda r)}{\Delta_{0}}$

and $\eta=(\mu-1) \theta(1-\lambda) \mathrm{r}+\delta \mu+\mathrm{r}$.

Letting $E\left(M_{t}\right)$ and $E\left(i_{t}\right)$ denote the expected value of these variables, the long-run response of money and the interest rate to a change in the reserve aggregate is

$$
\begin{aligned}
& \frac{\partial \mathrm{E}\left(\mathrm{M}_{t}\right)}{\partial \mathrm{R}_{\mathrm{t}}}=\frac{\alpha}{\alpha(\delta+r)+(1-\mu) \rho} \\
& \frac{\partial \mathrm{E}\left(\mathbf{i}_{\mathrm{t}}\right)}{\partial \mathrm{R}_{\mathrm{t}}}=\frac{1-\mu}{\alpha(\delta+\mathbf{r})+(1-\mu) \rho}
\end{aligned}
$$

long-run equilibrium in these models if their effect is sufficiently large relative to $\mu$

${ }^{17}$ This is the result obtained by Laufenberg. He bases his result on a comparison of basic LRA and CRA models with $\mu=0$; his CRA model is completely static while his LRA model is dynamic. Thus, his long-run LRA multiplier was always less than his instantaneous LRA multiplier. See Laufenberg, "Contemporary Versus Lagged Reserve Accounting." 
These results require the stability condition $|\xi|<1$.

Note that the long-run effect of a given change in the reserve aggregate does not depend on $\theta$ : it is invariant to the reserve accounting system. ${ }^{18}$ The reserve accounting system affects only the dynamic adjustment toward long-run equilibrium, and then only if depository institutions follow a path different from the one they otherwise would have followed. Furthermore, a comparison of the long-run money multiplier above with the instantaneous multiplier of equation 5 shows that, under CRA $(\theta=1)$, the long-run multiplier is strictly smaller only if $\mu=0$, but may be larger or smaller if $\mu>0$, as discussed above. ${ }^{19}$

\section{Effects on the Variabilty of Money and Inierest Rates}

We turn now to the important question of the variability of money and interest rates under LRA and CRA. In order to simplify the analysis, the following assumptions are made:

$$
\mathbf{E}\left(u_{i t} u_{j t^{\prime}}\right)\left\{\begin{array}{l}
=\sigma_{i}^{2} \text { for } t=t^{\prime} \text { and } i=j \\
=0 \text { for } t \neq t^{\prime} \text { or } i \neq j
\end{array} \quad i, j=e, m .\right.
$$

Given these assumptions, the variance of money and the interest rate for a $k$-period time horizon can be expressed as

$$
\begin{aligned}
& \operatorname{Var}\left(\mathbf{M}_{k}^{k}\right)=\left[\left[\frac{\alpha}{\Delta_{0}}\right\}^{2} \sigma_{e}^{2}+\left[\frac{\rho}{\Delta_{0}}\right]^{2} \sigma_{m}^{2}\right] \downarrow \\
& \left.\operatorname{Var}\left(\mathbf{i}_{\mathrm{k}}^{\mathrm{k}}\right)=\left(\left[\frac{1}{\Delta_{0}}\right]^{2}+\left[\frac{\alpha \boldsymbol{\eta} \eta}{\Delta_{0}^{2}}\right]\right]^{2} \psi\right) \sigma_{s}^{2}+\left(\left[\frac{\mathrm{r} \theta(1-\lambda)+\delta}{\Delta_{0}}\right]^{2}\right. \\
& \left.+\left[\frac{\eta p}{\Delta_{0}^{2}}\right]^{z} \psi\right) \sigma_{\mathfrak{m}}^{2}, \text { where } \psi=\frac{1-\xi^{2(k+1)}}{1-\xi^{2}} .
\end{aligned}
$$

It seems appropriate to consider the variance around the long-run equilibrium. If the variance of money and the interest rate around their longwrun equilibria are denoted by $\operatorname{Var}\left(M_{t}^{*}\right)$ and $\operatorname{Var}\left(i_{t}^{*}\right)$, respectively, then

\footnotetext{
${ }^{18}$ It may seem odd that the long-run equilibrium is independent of $\theta$ and $\lambda$ but not of $\mu$. To see why this is the case, note that in longm run equilibrium, where $\mathrm{M}_{\mathrm{t}}=\mathrm{M}_{\mathrm{t}-1}=\ldots$ and $\mathrm{RR}_{\mathrm{t}}=\mathrm{RR}_{\mathrm{t}-1}=\ldots$, the parameters $\theta$ and $\lambda$ drop out of equations 2 and 3 , respectively. This is not true of $\mu$ in equation 4 . This would be the case even if a growth rate model had been specified.

${ }^{19}$ Compare $\frac{\alpha}{\alpha(\delta+\theta)+(1-\mu) \rho}$ with $\frac{\alpha}{\alpha(x \theta(1-\lambda)+\delta)+\rho}$. The long run multipfier will be larger, equal to or smaller than the initial multiplier, depending on whether $\alpha^{2} r(\theta-1)-\alpha^{2} \theta r \lambda+\alpha \mu \rho \geq 0$. If $\mu=0$, this expression will be strictly negative. If $\mu>0$, this expression could be positive or negative, depending on the relative magnitudes of the various parameters.
}

$$
\operatorname{Var}\left(M_{t}^{*}\right)=\lim _{k \rightarrow \infty} \operatorname{Var}\left(M_{t}^{k}\right)
$$

and

$$
\operatorname{Var}\left(\mathbf{i}_{\mathrm{t}}^{*}\right)=\lim _{k \rightarrow \infty} \operatorname{Var}\left(\mathbf{i}_{\mathrm{t}}^{\mathrm{k}}\right)
$$

These expressions reduce to

(10) $\operatorname{Var}\left(M_{t}^{*}\right)=\frac{(\alpha)^{2} \sigma_{e}^{2}}{\Gamma}+\frac{\rho^{2} \sigma_{n}^{2}}{\Gamma}$

and

$$
\text { (11) } \begin{aligned}
\operatorname{Var}\left(\mathbf{i}_{\mathrm{t}}^{*}\right) & =\left(\left(\frac{1}{\Delta_{0}}\right)^{2}+\frac{(\alpha \eta)^{2}}{\Delta_{0}^{2} \Gamma}\right) \sigma_{e}^{2} \\
& +\left(\left(\frac{\mathrm{r} \theta(1-\lambda)+\delta}{\Delta_{0}}\right)^{2}+\frac{(\eta \rho)^{2}}{\Delta_{0}^{2} \Gamma}\right) \sigma_{\mathrm{TR},}^{2}
\end{aligned}
$$

where $\Gamma=[\alpha(r \theta(1-\lambda)+\delta)+\rho]^{2}-[\rho \mu-\alpha(r(1-\lambda)(1-\theta)+\lambda r)]^{2}$.

These expressions are independent of $\theta$ if $\lambda=1$. That is, if depository institutions already behave under CRA as LRA would require them to behave, the introduction of LRA would have no effect on the variance of money or interest rates. If $\lambda<1$, however, the move to LRA will increase the variance of money and may increase the variance of interest rates, depending (in part) on the relative magnitude of the variance of supply-side and demand-side shocks: the variance of interest rates is smaller under LRA the larger the variance of demand-side shocks. The essential conclusion, however, remains: the increase in the variance of money associated with a shift in the reserve accounting system from CRA to LRA is smaller the closer depository institutions conform to LRA behavior already - in this model, the closer $\lambda$ is to 1 .

\section{A Graphical Presentation of The Results}

The results are summarized conveniently in figures 2 and 3 . Note that the variances of equilibrium money stock and interest rates given in equations 10 and 11 have both demand-side and supply-side components. That is, they depend on both $\sigma_{e}^{2}$ and $\sigma_{\mathrm{m}}^{2}$. Thus, the variance of $\mathrm{M}^{*}$ can be decomposed into $\boldsymbol{\sigma}_{\mathrm{n}}^{\mathrm{d}} *+$ $\sigma_{\mathrm{m}}^{\mathrm{s}}$, where $\sigma_{\mathrm{m}}^{\mathrm{d} *}$ and $\sigma_{\mathrm{m}}^{\mathrm{s}} *$ denote the variance of $\mathrm{M}^{*}$ due solely to demand- and supply-side shocks, respectively. The variance of $i^{*}$ can be decomposed likewise.

Given the probability density function of $u_{m}$ and $u_{e}$, it is conceptually possible to construct a probability region for $\sigma_{\mathrm{in}}^{\mathrm{d} *}$ and $\sigma_{\mathrm{m}}^{\mathrm{s}} *$ from the corresponding region for $u_{m}$. This can be done for supply-side shocks as well. 


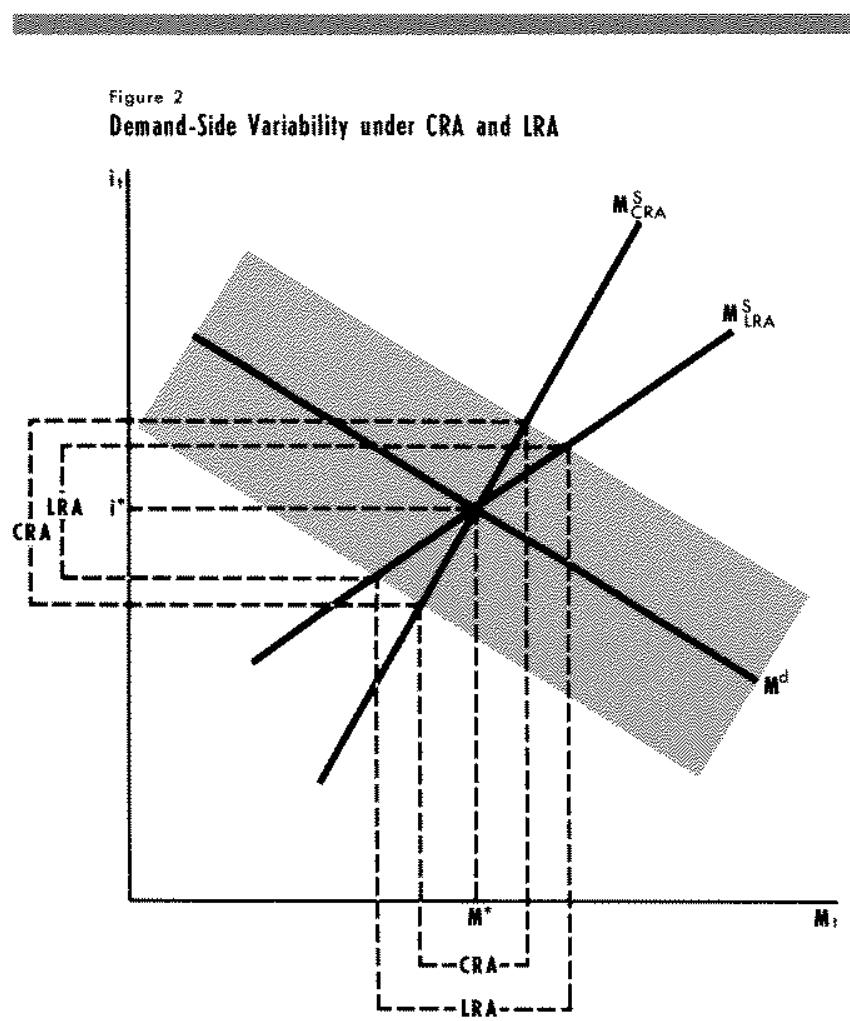

Figure 2 shows a hypothetical 95 percent region for both $\mathrm{M}^{*}$ and $\mathrm{i}^{*}$ associated with a corresponding 95 percent region of demand-side shocks. The region for $M^{*}$ is larger under LRA than under CRA because the slope of the money supply schedule is flatter under LRA. By the same token, however, the region is smaller for $i^{*}$ under LRA. The slope of the LRA curve approaches that of the CRA curve as $\lambda$ approaches 1 . If $\lambda=1$, the curves coincide and the variability of $M^{*}$ and $i^{*}$ associated with demand-side shocks is independent of the reserve accounting system.

Figure 3 shows the 95 percent region for $i^{*}$ and $M^{*}$ associated with the corresponding 95 percent region for supply-side shocks. Both regions are larger under LRA because the corresponding supply-side component multipliers (equations 10 and 11) are larger. These multipliers for LRA approach those for CRA as $\lambda$ approaches 1 . If $\lambda=1$, these multipliers are identical and the variability of $i^{*}$ and $M^{*}$ associated with supply-side shocks is independent of the reserve accounting system.

Thus, if banks initially relied on changes in excess reserves (or the discount window or the money market)

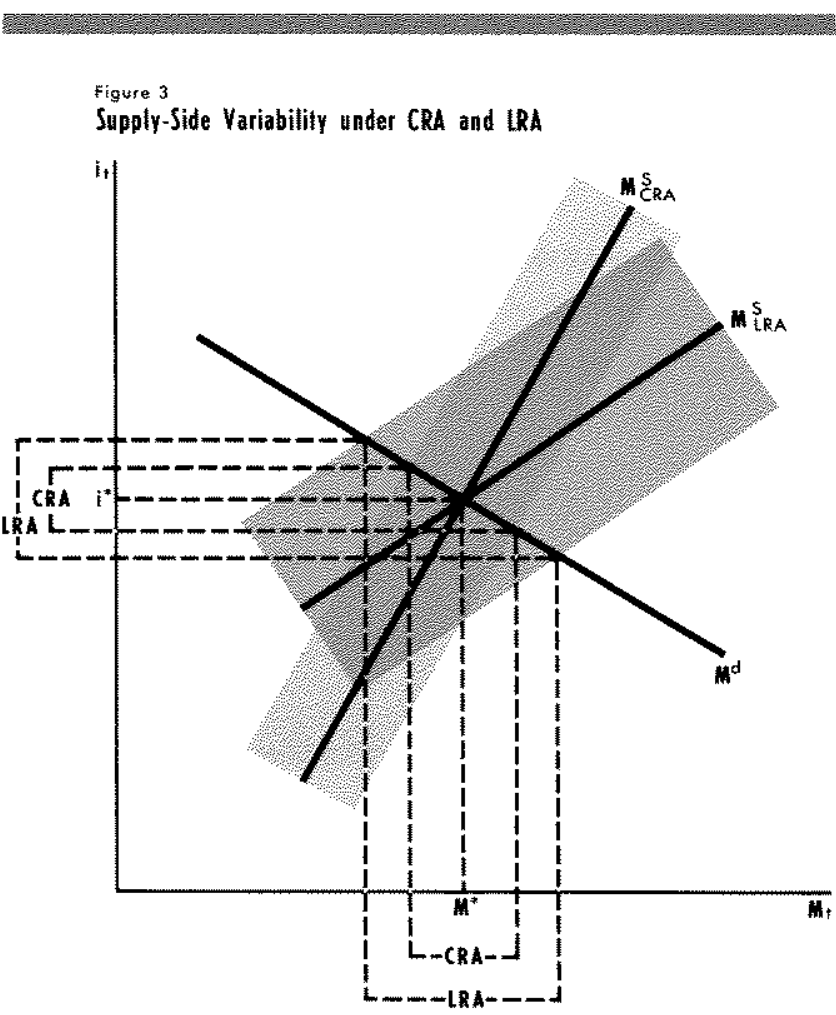

to adjust to short-run changes in required reserves before the introduction of LRA in September 1968, the effect of its introduction on the variability of money and interest rates would have been considerably less than previous theoretical work would indicate. Moreover, the return to CRA may not reduce the variability of money and interest rates as much as many analysts anticipate, if depository institutions do not change the manner in which they make short-run adjustments in their reserve positions.

Furthermore, it could be argued that the new procedure for CRA may have a minimal effect because it lengthens the reserve accounting period from one to two weeks. Thus, even if depository institutions make loans in the current period regardless of the consequences of these activities on required reserves under LRA, this practice may not be reduced markedly because of the lengthening of the reserve accounting period. Depository institutions may continue to make loans early in the period, waiting to settle (perhaps at the discount window, the money market or through changes in excess reserves) toward the end of the period. Of course, curtailment of lending activities will affect their current-period reserve requirements under CRA, but not under LRA. 


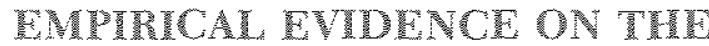 VAPANCE OF MONEY AND WNTEREST RATES}

Given that the effect of the reserve accounting system on the variability of money and interest rates appears to be in doubt, it would be desirable to estimate this effect. Unfortunately, empirical estimates from historical data may be of limited value. The observed variability of money and interest rates is a function of both the random components of the model and of movements associated with changes in the policy variable through time, as well as of changes in the structure of the system due to other changes, such as the introduction of LRA. This fact, coupled with documented and undocumented changes in the objectives of monetary policy, makes it difficult to separate the effect of the reserve accounting structure alone on the variability of money and interest rates. Nevertheless, it may be interesting to examine the data to see if a picture consistent with increased variability under LRA emerges.

Three measures of variability are used: two relative measures, the coefficient of variation (CV) and the average absolute percentage change (AAPC), and one absolute measure, the standard deviation $(\mathrm{SD}){ }^{20}$ Weekly data are used for various subperiods from January 1966 to November 1982. The subperiods were chosen on the basis of the introduction of LRA on September 12, 1968, and on the basis of announced changes in Federal Reserve procedures. ${ }^{21}$ The three measures of variability, and the mean $(\mathrm{X})$ of $\mathrm{Ml}$ appear in table 1 . The same statistics appear in table 2 for the federal funds rate, the 3-month Treasury bill rate and the $4-6$ month commercial paper rate.

\footnotetext{
The standard deviation is not independent of the unit of measure; $S D(k x)=k S D(x)$, where $k$ is a constant. Thus, if the level of the variable increases through time, the $S \mathrm{D}$ will increase even if the variability relative to the mean has not changed. The coefficient of vartation adjusts for this effect.

${ }^{21}$ Lagged reserve accounting was introduced on September 12 , 1968 ; at its January 15, 1970, meeting, the Federal Open Market Committee stated a desire to place increased emphasis on the growth of certain monetary aggregates; Congress passed Resolution 133 on March 24, 1975 , requesting that the Board of Govemors set long-run ranges for the aggregates; the Federal Open Market Committee adopted a reserve aggregate targeting procedure on October 6, 1979. See Jerry L. Jordan and Nell A. Stevens, "The Year 1970. A Modest Beginning for Monetary Aggregates, this Review (May 1971), pp. 14-32, Nancy Jianakoplos, "The FOMC in 1975: Announcing Monetary Targets" this Review (March 1976), pp. 8-22; and Richard W. Latng, "The FOMC it 1979: Introducing Reserve Targeting," this Review (March 1980), pp. $2-25$.
}

\section{Table 1}

\section{Measures of Absolute and Relative Variability of M1}

\begin{tabular}{|c|c|c|c|c|}
\hline \multirow[b]{2}{*}{ Perrod' } & \multicolumn{4}{|c|}{$n(S A)$} \\
\hline & AAPC & $\mathrm{so}$ & ov & $x^{2}$ \\
\hline $9,511,68$ & $16 \%$ & 5.7 .28 & 406 & 8779.69 \\
\hline 9.1860 & $\sqrt{12}$ & 307 & 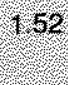 & 20209 \\
\hline (1,22/75 & $\sqrt{16}$ & 23.16 & 950 & 24673 \\
\hline $\begin{array}{l}4 / 275 \\
10.379\end{array}$ & (7) & 31.18 & 059 & \\
\hline 11110179 & 36 & 24.93 & 587 & 42462 \\
\hline
\end{tabular}

These data show that there was no increase in the week-to-week absolute or relative variability of $\mathrm{MI}$ immediately after the introduction of LRA in September 1968. If anything, there was a reduction in variability. ${ }^{22}$ Furthermore, though there was an in. crease in the absolute variability of the federal funds and the Treasury bill rates, there was essentially no change in the relative variability. The exception was the commercial paper rate. It became more variable in both absolute and relative terms. ${ }^{23}$ These data are broadly at odds with the general conclusion that the move to LRA increased the variability of money and interest rates.

Of course, one could argue that the theoretical results of the previous section are based on a model in which money is controlled through reserve aggregate targeting, and that the Federal Reserve was operating on an interest rate target during this period. Thus, the results of the theoretical model may not be forthcoming over this period. Even an interest rate targeting

\footnotetext{
${ }^{22}$ If one assumes that the absolute percentage change has a positive and finite variance, then one can rely on the Central Limit Theorem to construct an asymptotic " $t$-test" of the differences ir the AAPC for two sulpperiods. The t-ratio for the test of the first against the second subperiod was -2.75 for $\mathrm{Ml}$, indicating a significant reduction (at the 5 percent level) in the AAPC for MI after the introduction of LRA. See Robert $V$. Hogg and Allen T. Craig, Introduction to Mathematical Statistics, 4 th ed. (MacMillan 1978), p. 192, for the conditions necessary to invoke the Central Limit Theoren.

${ }^{23}$ The asymptotic tratios for FFR, TBR and CPR for the AAPC were $1.56,-0.87$ and 2.82 , respectively. See footnote 22 for details.
} 


\section{Table 2}

\section{Measures of Absolute and Relative Variability of Three Interest Rates}

\begin{tabular}{|c|c|c|c|c|c|c|c|c|c|c|c|c|}
\hline \multirow[b]{2}{*}{ Period } & \multicolumn{4}{|c|}{ Federal Funds gate' } & \multicolumn{4}{|c|}{ Treasury Bill nate } & \multicolumn{4}{|c|}{ Commercial paper nale } \\
\hline & Ampe & so & cV & $\mathrm{x}$ & $\mathrm{AAPC}$ & $\mathrm{SP}$ & ov & $\mathrm{x}$ & $\mathrm{AAPO}$ & 80 & ov & $x$ \\
\hline $9 / 1,660$ & $5.10 \%$ & $0.76 \%$ & 15.51 & $1489 \%$ & $1.66 \%$ & $0.53 \%$ & 1106 & $476 \%$ & $0.65 \%$ & $0446 \%$ & 8.56 & $5.48 \%$ \\
\hline $9 / 1806$ & 636 & 4.97 & 1795 & 761 & 1,48 & 0.75 & 1160 & 6.44 & 1.13 & 112 & 1506 & 7.44 \\
\hline 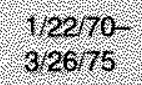 & 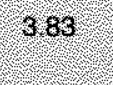 & 2.58 & 6.67 & 705 & 292 & 163 & 2760 & 592 & 199 & 2,15 & 30,34 & 708 \\
\hline 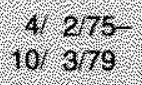 & $1+61$ & 2.05 & 3024 & 6.80 & 1,73 & $\sqrt{17}$ & 26.59 & 6.13 & 1.25 & 192 & 2750 & 6.97 \\
\hline$\frac{10 / 1079}{1,26102}$ & 445 & 300 & 21.81 & 1413 & 384 & 2.56 & 27,12 & 12,13 & 8.90 & 265 & 19.90 & 13.34 \\
\hline
\end{tabular}

procedure, however, requires the Federal Reserve to forecast money demand. Hence, errors in short-run money demand forecasts should have produced more variable money under LRA.

The Federal Reserve placed more emphasis on monetary aggregates in March 1970 and set long-run targets for the aggregates beginning in 1975. Assuming no other change occurred that would affect the variability, one might expect the variability of M1 to increase in these subperiods relative to the pre-LRA period. Here the results are mixed. Both the SD and the $\mathrm{CV}$ show an increase in the variability of $\mathrm{Ml}$, while the AAPC shows essentially no change. Broadly similar results are obtained for the three interest rates in table 2. The only significant increase in the AAPC for M1 comes with the Federal Reserve's adoption of reserve aggregate targeting in October 1979.

\section{CONKLUSONS}

The analysis presented in this article indicates that the type of reserve accounting structure has no effect on the long-run equilibrium money stock; it can, however, influence the dynamic path to equilibrium if it forces depository institutions to adjust their reserve positions differently than they would have done other- wise. In this instance, the variance of money would increase with the shift from CRA to LRA and the variance of the interest rate might increase as well, depending on relative variability of demand-and supply-side shocks. In the absence of more detailed information about the exact nature of the dynamic ad justment process, the question of whether money or interest rates are more variable under CRA or LRA is empirical.

Unfortunately, the observed variability of money and interest rates is not simply a function of the reserve accounting system; it depends also on the random components of the model and movements associated with changes in the policy variable through time. Thus, it is difficult to assess the effect of changes in the reserve accounting structure alone on the observed variability of money and interest rates. The simple evidence from weekly data does not give a clear picture of whether the movement to LRA in September 1968 increased the variability of money and interest rates. The results differ depending on the measure of variability one uses. Nevertheless, if the average absolute percentage change is used as the measure of variability, there was no significant change in the week-to-week variability of M1 from January 5, 1966 , to November 3, 1979. 